\title{
Geraniin inhibits bladder cancer cell growth via regulation of PI3K/AKT signaling pathways
}

\author{
Junwei $\mathrm{Xu}^{1}$, Ning Qin ${ }^{2}$, Yebin Yao ${ }^{3}$, Tao Chen ${ }^{1}$, Wenbo Jiang ${ }^{4 *}$ \\ ${ }^{1}$ Department of Traditional Chinese Medicine, Affiliated Hospital of Nantong University, ${ }^{2}$ Department of Medical Nursing \\ Teaching and Research, Nantong Health College of Jiangsu Province, ${ }^{3}$ Department of Infectious Diseases, Affiliated Hospital of \\ Nantong University, Nantong City, Jiangsu Province 226001, 4Department of Cardiovascular Medicine, Suqian Hospital of \\ Traditional Chinese Medicine, Suqian City, Jiangsu Province 223800, China
}

*For correspondence: Email: WenboJiangdgh@163.com; Tel: +86-527-82966829

\begin{abstract}
Purpose: The effect of geraniin on human bladder transitional carcinoma was not clear, this study was thus intended to reveal it and reveal the mechanism.

Methods: T24 cells were treated with 5, 10, and $20 \mu \mathrm{M}$ of geraniin and the viability and apoptosis of T24 cells were determined using thiazolyl blue tetrazolium bromide (MTT) assay and flow cytometry. The protein expression levels of Cyclin D1, p21, BAL-2, BAX, cleaved caspase-3 and PI3K/AKT pathway were evaluated using western blot.

Results: Geraniin decreased T24 cell viability and induced T24 cell cycle arrest. The proportion of T24 cells in S phase was decreased by geraniin. Besides, geraniin promoted T24 cell apoptosis and regulated PI3K/AKT pathway.

Conclusion: Geraniin appears to regulate bladder cancer cell growth by decreasing the levels of PI3K and AKT phosphorylation. Thus, this agent may be useful in the management of bladder cancer
\end{abstract}

Keywords: Geraniin, T24 cells, Apoptosis, PI3K/AKT signaling

\begin{abstract}
This is an Open Access article that uses a fund-ing model which does not charge readers or their institutions for access and distributed under the terms of the Creative Commons Attribution License (http://creativecommons.org/licenses/by/4.0) and the Budapest Open Access Initiative (http://www.budapestopenaccessinitiative.org/read), which permit unrestricted use, distribution, and reproduction in any medium, provided the original work is properly credited.

Tropical Journal of Pharmaceutical Research is indexed by Science Citation Index (SciSearch), Scopus, International Pharmaceutical Abstract, Chemical Abstracts, Embase, Index Copernicus, EBSCO, African Index Medicus, JournalSeek, Journal Citation Reports/Science Edition, Directory of Open Access Journals (DOAJ), African Journal Online, Bioline International, Open-J-Gate and Pharmacy Abstracts
\end{abstract}

\section{INTRODUCTION}

Bladder cancer is a malignant tumor that affects urinary system, which is now second only to prostate cancer with a higher incidence in urogenital tumor system [1]. Patients are commonly treated with neoadjuvant chemotherapy and surgery. Though common chemotherapy regimens are reported, the effective proportion ranges only from 40 to $65 \%$ [2], the development of new therapeutic drugs is thus necessary for increasing survival rate.
Botanically derived drugs, such as paclitaxel and camptothecin, are important for the treatment of malignant tumors due to their strong specific and pharmaceutical effects in cancer treatment. Besides, Phytohormones increase reactive oxygen species (ROS) levels in HL60 cells to stimulate caspase-3/7 activities and induce cell apoptosis. It has also been shown that scutellarin inhibits the dissociation and degradation of SKP2 by SKP1, which causes lung cancer cell line A549 to arrest in the G2/M phase [3]. In 
particular, Geraniin is one of the typical natural scented tannin that has antioxidant, anti-viral, and anti-bacterial effects $[4,5]$.

Related studies have demonstrated that geraniin could inhibit migration, invasion, and drug resistance in transforming growth factor- $\beta 1$ treated A549 cells [6]. Geraniin induces breast cancer cell apoptosis by regulating the ROSstimulated p38 mitogen-activated protein kinase pathway [7].In human colorectal cancer cells, by inducing chromosomal instability of mutations, geraniin could selectively arrest cell cycle [8]. In ovarian cancer cells, geraniin inhibits cell growth by inhibiting the nuclear factor-KB pathway and decreasing MCL-1 expression. In addition, geraniin reverses the resistance of human colon cancer cell line (HCT-8) to fluorouracil, cisplatin, and vincristine. The expression of the multidrug resistance gene MDR1 may be inhibited by preventing nuclear translocation of the transcription factor YB1 [9-11]. Though Geraniin is an anti-tumor compound derived from traditional Chinese medicine, its anti-tumor effects and the underlying mechanism in bladder cancer is still unclear.

\section{EXPERIMENTAL}

\section{Chemicals}

Dulbecco's Modified Eagle Medium (DMEM), dimethyl sulfoxide (DMSO), fetal bovine serum (FBS) phosphate-buffered saline (PBS) and TRIzol reagent were obtained from Invitrogen (Carlsbad, CA, USA). Geraniin was obtained from Sigma, St. Louis (MO, USA) with a purity of above $80 \%$. Annexin V-FITC/PI Apoptosis Detection kit was obtained from Beyotime (Shanghai, China). 3, 3'-diaminobenzidine (DAB) and bicinchoninic acid protein (BCA) assay were purchased from Phygene Lifescience (China).

\section{MTT}

Human bladder transitional carcinoma cell line T24 in the logarithmic growth phase was digested, centrifuged, and the supernatant was discarded. Cell density was adjusted to $8 \times 10^{4}$ cells $/ \mathrm{mL}$ with medium and inoculated with $100 \mu \mathrm{L}$ per well. After $24 \mathrm{~h}$ of incubation, 5, 10, or $20 \mu \mathrm{M}$ geraniin was added and then incubated and MTT was added. After removing the supernatant, DMSO was added and the absorbance was measured at $490 \mathrm{~nm}$.

\section{Flow cytometry}

The harvested T24 cells were inoculated for 24 $h$, and then were treated with 5,10 , or $20 \mu \mathrm{M}$ geraniin. 24h later, cells were collected and then washed twice with pre-cooled PBS. The staining reagents were added and incubated in the dark. Flow cytometry was performed by standard procedure.

To assess cell apoptosis, T24 cells that treated by geraniin were collected using centrifugation, washed by PBS, and suspended in binding buffer. Next, Annexin V-FITC and PI was added, mixed and measured.

\section{Western blot}

The T24 cells were treated with 5,10 , or $20 \mu \mathrm{M}$ geraniin for $24 \mathrm{~h}$, followed by lysed and centrifuged. Membranes were blocked and the Protein Gel Electrophoresis Chamber Systems (Cat. No. El0001, Invitrogen) was performed at $100 \mathrm{~V}$ for about $90 \mathrm{~min}$. Then, membranes were washed and incubated with the following antibodies overnight at $4{ }^{\circ} \mathrm{C}$.

The primary antibodies (diluted 1:1,000) were as follows: cleaved caspase-3 (Asp 175, 9661\#, Cell Signaling, USA), Cyclin D1 (Human Specific, MAB60001-SP, R\&D System, USA), p21 (Human Specific, 9502\#, R\&D System, USA), BAX antibody (human, ab32503, Abcam, USA), BCL-2 (human, AF810-SP, R\&D System, USA), Human PI3-Kinase Antibody (MAB2686-SP, R \& D System, USA), PI3K (phospho Y464, ab138364, Abcam, USA), Human AKT (MAB2055-SP, R\&D System, USA), and Human Phospho-AKT (MAB877-SP, R \& D System, USA).

The secondary antibody was horseradish peroxidase-labeled goat anti-human immunoglobulin $G(H+L)$ (diluted 1:500, A0201, Beyotime, China). The internal reference protein was $\beta$-actin (human, MAB8969-SP, R\&D System, USA). TBST washes were then performed five times before chemiluminescence detection.

The gel was resuspended in $100 \mu \mathrm{L}$ of loading dye and separated using $7.5 \%$ polyacrylamide gel electrophoresis. The target protein in chemiluminescence was detected using ChemiDocTM XRS + gel imaging system.

\section{Statistical analysis}

Analysis was performed using SPSS (USA) 13.0 statistical software. Data were expressed as mean \pm standard deviation. Data were analyzed using t-tests and one-way analysis of variance. Differences were considered significant at $p<$ 0.05 . 


\section{RESULTS}

\section{Geraniin decreased T24 cell viability}

Figure 1 showed the viability of T24 cells after treatment with geraniin for 24-h. Compared with the control group, there was a significant decrease when treated with geraniin $(p<0.05)$. When the concentrations of geraniin were 5,10 , and $20 \mu \mathrm{M}$, the rates of cell viability were 80.7 , 57.5 , and $45.7 \%$, respectively. The viability of T24 cells was decreased dose-dependently, with a half-maximal inhibitory concentration $\left(\mathrm{IC}_{50}\right)$ value of $16.43 \mu \mathrm{M}$. These findings show that geraniin reduced $\mathrm{T} 24$ cell viability.

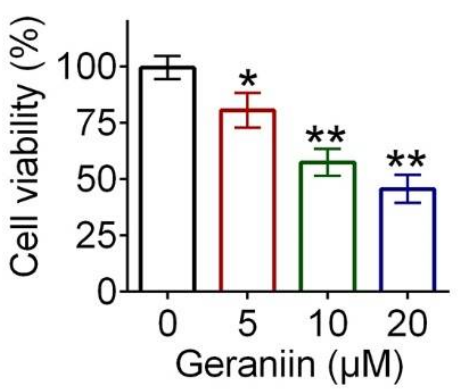

Figure 1: Effect of geraniin on the viability of T24 cells; ${ }^{*} p<0.05,{ }^{* *} p<0.01$ vs. control group, $\mathrm{n}=3$

\section{Geraniin induced cell cycle arrest in T24 cells}

Cyclin D1, a positive regulator of G1/S phase, forms a regulatory pathway with p21, could prevent cells from entering $S$ phase and thus limit cell overgrowth. As shown in Figure 2A, when the concentration of geraniin was 5, 10, and $20 \mu \mathrm{M}$, T24 cells in $\mathrm{G} 1$ phase was 67.09 , 76.69 and $88.74 \%$ and T24 cells in the S phase was 28.36, 18.91, and $6.13 \%$, respectively. Figure $2 \mathrm{~B}$ showed that the protein expression levels of Cyclin D1 and p21 was down-regulated $(p<0.01$ vs. control), and up-regulated $(p<0.01$ vs. control) by geraniin. These results showed that geraniin could induce T24 cell cycle arrest.

\section{Geraniin promoted T24 cell apoptosis}

When geraniin concentrations were 5,10 , and 20 $\mu \mathrm{M}$, the apoptotic proportion were $18.5 \%, 30.2$ $\%$, and $36.5 \%(p<0.05, p<0.01$ and $p<0.01$ vs. control, respectively). Moreover, in T24 cells that treated with 5,10 , and $20 \mu \mathrm{M}$ of geraniin, the early apoptotic proportions were 10.3, 20.9, and $21.3 \%$, while the late apoptotic proportions were $7.46,9.28$, and $16.0 \%$, respectively (Figure $3 \mathrm{~A}$ ). Totally, geraniin promoted T24 cell apoptosis.
The results in Figure 3B showed that, after T24 cells were treated with geraniin, the protein expression levels of BAX and cleaved caspase3were up-regulated, and the anti-apoptotic protein BCL-2 was down-regulated (all $p<0.01$ vs. control).

A
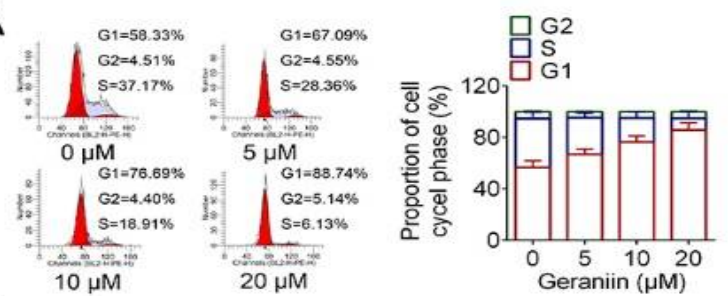

B
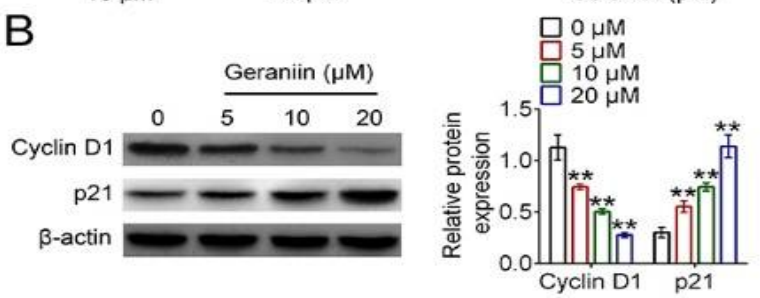

Figure 2: Effect of geraniin on T24 cell cycle arrest. (A) Cell cycle analysis was performed by flow cytometry. (B) Cyclin D1 and p21 protein expression levels were detected by western blot; ${ }^{*} p<0.05$, ${ }^{* *} p<$ 0.01 vs. control group, $\mathrm{n}=3$
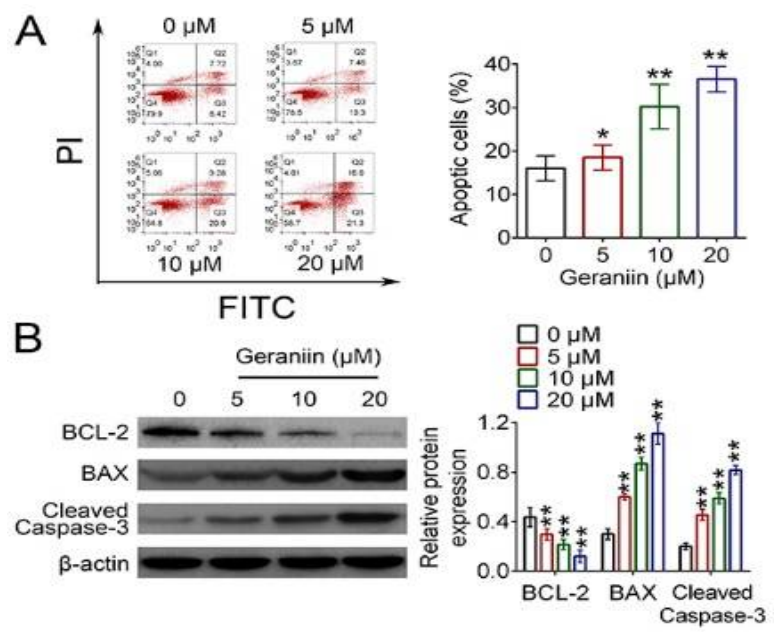

Figure 3: Effect of geraniin on the expression of apoptosis related proteins. (A) Cell apoptosis was detected by flow cytometry. (B) The protein expression levels were measured by using western blot; ${ }^{*} p<0.05$, ${ }^{* *} p<0.01$ vs. control group, $\mathrm{n}=3$

\section{Geraniin regulated PI3K/AKT pathway}

Western blotting was used for detecting the protein expressions of apoptotic pathway. The results were shown in Figure 4. The protein expression levels of $\mathrm{p}$-PI3K and $\mathrm{p}$-AKT were down-regulated (all $p<0.01$ vs. control group), butPI3K and AKT were not significantly affected. The ratios of $\mathrm{p}-\mathrm{PI} / 3 \mathrm{~K} / \mathrm{PI} / 3 \mathrm{~K}$ and $\mathrm{p}-\mathrm{AKT} / \mathrm{AKT}$ were 
decreased when the concentration of geraniin was increased ( $p<0.01 \mathrm{vs.} \mathrm{control} \mathrm{group).}$

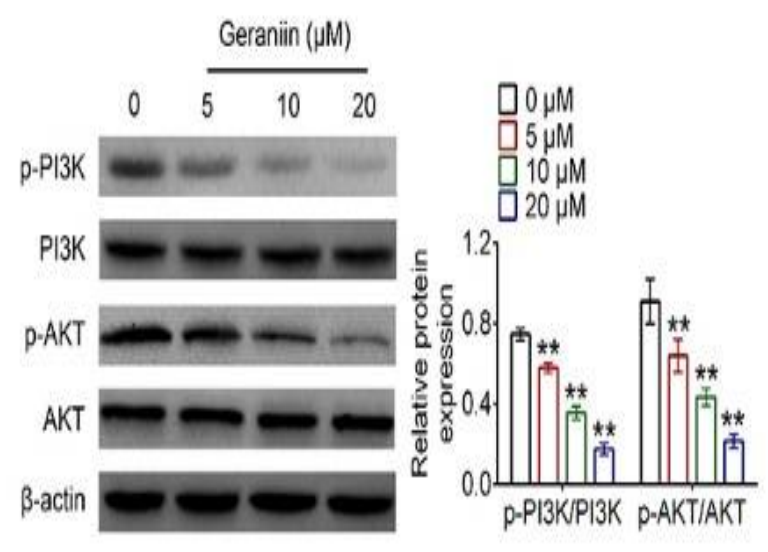

Figure 4: Effect of geraniin on PI3K/AKT pathway. Western blot was used for detecting the protein expression levels; ${ }^{* *} p<0.01$ vs. control group, $\mathrm{n}=3$

\section{DISCUSSION}

Bladder transitional cell carcinoma is the most common type seen (about $90 \%$ ) in bladder cancer patients $[12,13]$. Thus, T24 cells were used in this study. Geraniin a yellow crystalline polyphenolic compound, has been reported to induce apoptosis of T24 cells which might has potential for possible cancer treatment [14].

Apoptosis is gene-regulated cell death, and it is extremely important for maintaining internal environmental stability and normal physiological activities. Tumors achieve unlimited proliferation through escape of programmed death [15]. This study demonstrated that geraniin has an antitumor effect by inhibiting the growth of T24 cells. In detail, geraniin inhibited the viability, caused the cessation of $S$ phase in the cell cycle, downregulated the receptor proteins cyclin D1 and $\mathrm{p} 21$, and induced cell apoptosis in T47 cells.

Bcl-2 family regulates mitochondria permeability via a mechanism in which cells receive a signal for apoptosis, and Bax is oligomerized and transferred from the cytoplasm to the outer membrane of the mitochondria [16]. Bax then interacts with the anion channels on the membrane, releasing apoptotic factors from the mitochondria into the cytoplasmic matrix. Bcl-2 forms a dimer with pro-apoptotic Bax. If the relative amount of $B a x$ is higher than that of $B C L-$ 2 , the number of BAX homodimers increases, leading to the opening of the mitochondrial permeability transition pore, and activates caspase-3 downstream. Caspase-3 is important for the apoptotic process [17]. Here, cleaved caspase-3 was up-regulated, indicating that geraniin induced apoptosis of T24 cells, which may also require the participation of caspase family proteins.

The PI3K/AKT pathway is one of the pathways that regulate cell function [18]. Phosphatidylinositol 3-kinase (PI3K) is the initial part of this pathway $[19,20]$. The second messenger produced by PI3K can be used to transmit information to the cells, ultimately affecting cell proliferation, differentiation, survival, and migration. The PI3K/AKT signaling pathway is critical for the development and progress of tumors [21].

$s$ a protein kinase, AKT is activated by various growth and survival factors [22]. It is a key molecule in the PI3K-induced wortmannin sensitive signaling pathway and in regulating cell survival and apoptosis. Activation of AKT is accomplished by phosphorylation of Thr308 site of the activation loop and the Ser473 site. Activation of AKT requires simultaneous phosphorylation at both sites and thus promotes cell proliferation by inhibiting apoptosis. Based on the results in our study, it can be concluded that geraniin down-regulates PI3K/AKT signaling pathway to regulate cell growth by inhibiting viability and promoting apoptosis in T24 cells. However, the specific regulatory molecular mechanism of geraniin-induced apoptosis needs to be further studied.

\section{CONCLUSION}

Geraniin exerts anti-tumor effect in T24 cells by inhibiting cell viability and inducing cell apoptosis. Its anti-tumor activity is closely related to the apoptotic mechanism, PI3K/AKT pathway, which provides a pharmacological basis for the development of natural compounds for cancer treatment.

\section{DECLARATIONS}

\section{Conflict of interest}

No conflict of interest is associated with this work.

\section{Contribution of authors}

We declare that this work was done by the researchers listed in this article. All liabilities related with the content of this article will be borne by the authors. Junwei Xu designed all the experiments and revised the paper. Ning Qin and Yebin Yao performed the experiments, Tao Chen and Wenbo Jiang wrote the paper. 


\section{Open Access}

This is an Open Access article that uses a funding model which does not charge readers or their institutions for access and distributed under the terms of the Creative Commons Attribution License (http://creativecommons.org/licenses/by/ 4.0) and the Budapest Open Access Initiative (http://www.budapestopenaccessinitiative.org/rea d), which permit unrestricted use, distribution, and reproduction in any medium, provided the original work is properly credited.

\section{REFERENCES}

1. Redondo GE, de Castro LN, Moreno SJ, de las CM, Luisa M, Vera GV, Ferrari DG, Corchado JM. Bladder carcinoma data with clinical risk factors and molecular markers: a cluster analysis. BioMed Res Int 2015; 2015 : 1-14.

2. Williams SK, Hoenig DM, Ghavamian R, Soloway M. Intravesical therapy for bladder cancer. Exp Opin Pharm 2010; 11(Pt 6): 947-958.

3. Lin SY, Wang CC, Lu YL, Wu WC, Hou WC. Antioxidant, anti-semicarbazide-sensitive amine oxidase, and antihypertensive activities of geraniin isolated from Phyllanthus urinaria. Food Chem Toxicol 2008; 46(Pt 7): 2485-2492.

4. Ito $H$. Metabolites of the ellagitannin geraniin and their antioxidant activities. Planta Med 2011; 77(Pt 11): 1110 1115.

5. Kang KA, Lee IK, Zhang R, Piao MJ, Kim KC, Kim SY, Shin T, Kim BJ, Lee NH, Hyun JW. Radioprotective effect of geraniin via the inhibition of apoptosis triggered by $y$-radiation-induced oxidative stress. Cell Biol Toxicol 2011; 27(Pt 2): 83-94.

6. Ko H. Geraniin inhibits TGF- $\beta 1$-induced epithelialmesenchymal transition and suppresses A549 lung cancer migration, invasion and anoikis resistance. Bioorg Med Chem Lett 2015; 25(Pt 17): 3529-3534.

7. Zhai JW, Gao C, Ma WD, Wang W, Yao LP, Xia XX, Luo $M, Z u Y G, F u$ YJ. Geraniin induces apoptosis of human breast cancer cells MCF-7 via ROS-mediated stimulation of $p 38$ MAPK. Toxicol Mech Method 2016; 26(Pt 5): 311-318.

8. Guo $X$, Wang $H, N i J$, Liang $Z, W u X$, Xue J, Wang $X$. Geraniin selectively promotes cytostasis and apoptosis in human colorectal cancer cells by inducing catastrophic chromosomal instability. Mutagenesis 2018; 33(Pt 4): 271-281.

9. Wang $Y$, Wan $D$, Zhou R, Zhong W, Lu S, Chai Y. Geraniin inhibits migration and invasion of human osteosarcoma cancer cells through regulation of
PI3K/Akt and ERK1/2 signaling pathways. Anti-cancer Drug 2017; 28(Pt 9): 959-966.

10. Ren Z, Zou W, Cui J, Liu L, Qing Y, Li Y. Geraniin suppresses tumor cell growth and triggers apoptosis in human glioma via inhibition of STAT3 signaling. Cytotechnology 2017; 69(Pt 5): 765-773.

11. Wang $X$, Chen Z, Li $X$, Jiang Zk, Zhao Yq, Ping Ff. Geraniin suppresses ovarian cancer growth through inhibition of NF-KB activation and downregulation of Mcl1 expression. J Biochem Mol Toxic 2017; 31(Pt 9): e21929.

12. Kaufman DS, Shipley WU, Feldman AS. Bladder cancer. The Lancet 2009; 374(Pt 9685): 239-249.

13. Heney NM, Ahmed S, Flanagan MJ, Frable W, Corder MP, Hafermann MD, Hawkins IR. Superficial bladder cancer: progression and recurrence. J Urology 1983; 130(Pt 6): 1083-1086.

14. Phang SCW, Palanisamy UD, Kadir KA. Effects of geraniin (rambutan rind extract) on blood pressure and metabolic parameters in rats fed high-fat diet. $J$ Integr Med 2019; 17(Pt 2): 100-106.

15. Xie NS, Xie JF, Tang JH, Liu YS, Wei YF, Gu QP, Luo $Q T$, Zhu FQ. Alantolactone exerts anti-proliferative and apoptotic effects on BGC823 and SGC7901 cells via activation of p38MAPK and inhibition of NF-KB signaling pathway. Trop J Pharm Res 2019; 18(Pt 3): 465-470.

16. Rossé T, Olivier R, Monney L, Rager M, Conus S, Fellay I, Jansen B, Borner C. Bcl-2 prolongs cell survival after Bax-induced release of cytochrome c. Nature 1998; 391(Pt 6666): 496.

17. Porter AG, Jänicke RU. Emerging roles of caspase-3 in apoptosis. Cell Death Differ 1999; 6(Pt 2): 99.

18. Graziana DF, Daniele C, Roberta A, Silvia LM, Pier GP, Mara B, Andrea C. Overcoming Palbociclib Resistance by Combined Treatment with PIJK/AKT/mTOR Inhibitors in Mesothelioma Cells. J Mol Clin Med 2018; 1(Pt 3): 151-156.

19. Hennessy BT, Smith DL, Ram PT, Lu Y, Mills GB. Exploiting the PIBK/AKT pathway for cancer drug discovery. Nat Rev Drug Discov 2005; 4(Pt 12): 988.

20. Vara JÁF, Casado E, de Castro J, Cejas P, Belda IC, González BM. PI3K/Akt signalling pathway and cancer. Cancer Treat Rev 2004; 30(Pt 2): 193-204.

21. Digiacomo G, Fumarola $C$, Cretella $D$, Alfieri $R$, La MS, Petronini PG, Bonelli M, Cavazzoni A. Overcoming Palbociclib Resistance by Combined Treatment with PI3K/AKT/mTOR Inhibitors in Mesothelioma Cells. J Mol Clin Med 2018; 1(Pt 3): 151-156.

22. Gao X, Wang $Y$, Zhang J, Lin L, Yao Q, Xiang G. Bergenin suppresses the growth of colorectal cancer cells by inhibiting PI3K/AKT/mTOR signaling pathway. Trop J Pharm Res 2017; 16(Pt 10): 2307-2313. 